\title{
Full Stereochemical Assignment and Synthesis of the Potent Anthelmintic Pyrrolobenzoxazine Natural Product: CJ-12662
}

\author{
Charles Didier, ${ }^{\dagger}$ Douglas J. Critcher, ${ }^{\ddagger}$ Nigel D. Walshe, ${ }^{\ddagger}$ \\ Yasuhiro Kojima, ${ }^{\S}$ Yuji Yamauchi, ${ }^{\S}$ \\ Anthony G. M. Barrett ${ }^{\dagger} *$ \\ Supporting information
}

Table of contents

${ }^{1} \mathrm{H} /{ }^{13} \mathrm{C}$ NMR compound 4 : S-1

${ }^{1} \mathrm{H} /{ }^{13} \mathrm{C}$ NMR compound 9 : S-3

${ }^{1} \mathrm{H} /{ }^{13} \mathrm{C}$ NMR compound 10 : S-5

${ }^{1} \mathrm{H} /{ }^{13} \mathrm{C}$ NMR compound 11 : S-7

${ }^{1} \mathrm{H} /{ }^{13} \mathrm{C}$ NMR compound 13 : S-9

${ }^{1} \mathrm{H} /{ }^{13} \mathrm{C}$ NMR compound $14: \mathrm{S}-11$

${ }^{1} \mathrm{H} /{ }^{13} \mathrm{C}$ NMR compound $15: \mathrm{S}-13$

${ }^{1} \mathrm{H} /{ }^{13} \mathrm{C}$ NMR compound 16 : S-15

${ }^{1} \mathrm{H} /{ }^{13} \mathrm{C}$ NMR compound 1 : S-17

Thermal ellipsoid figure of 1 : S-19

Thermal ellipsoid figure of $16:$ S-20 


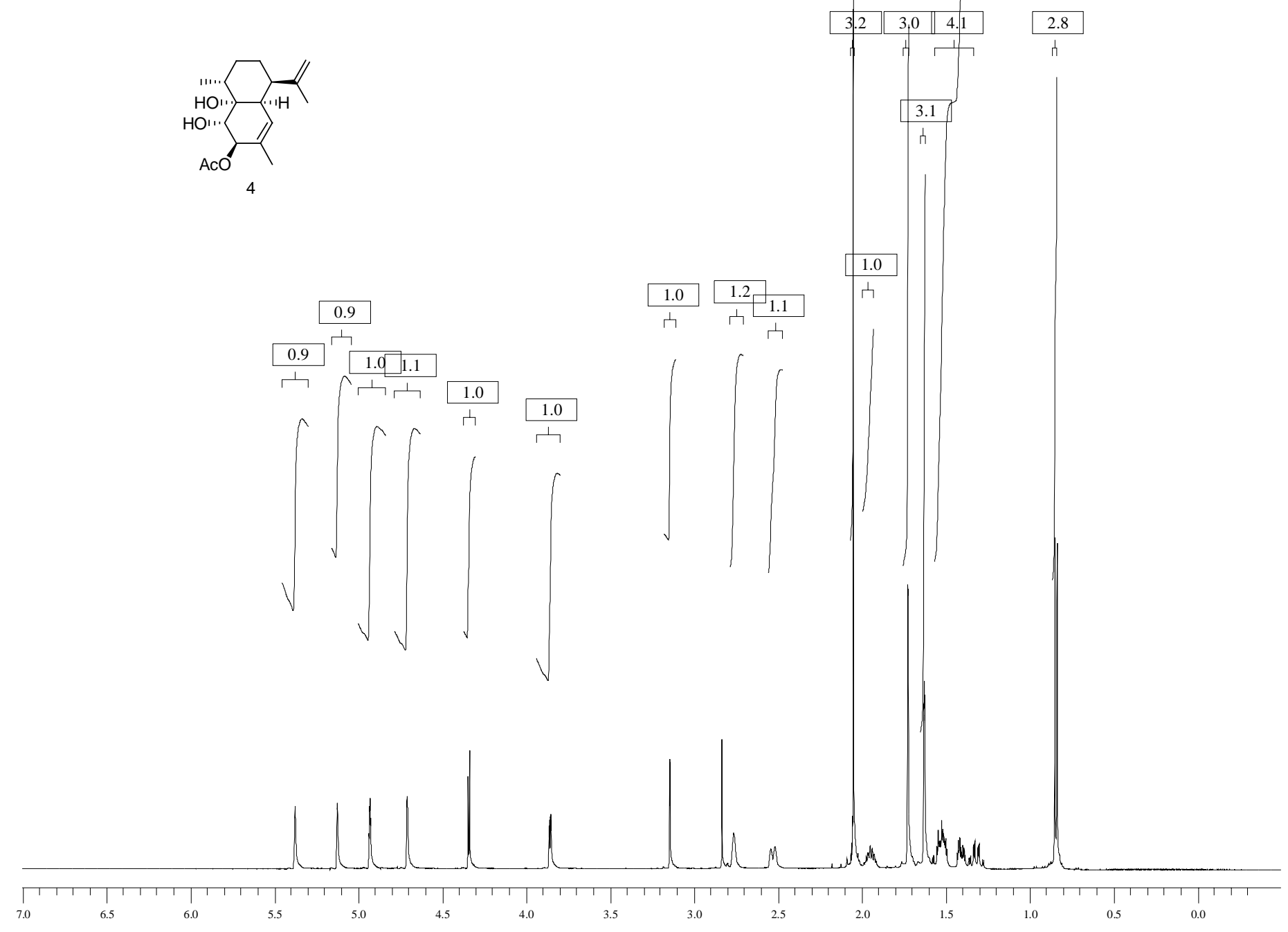




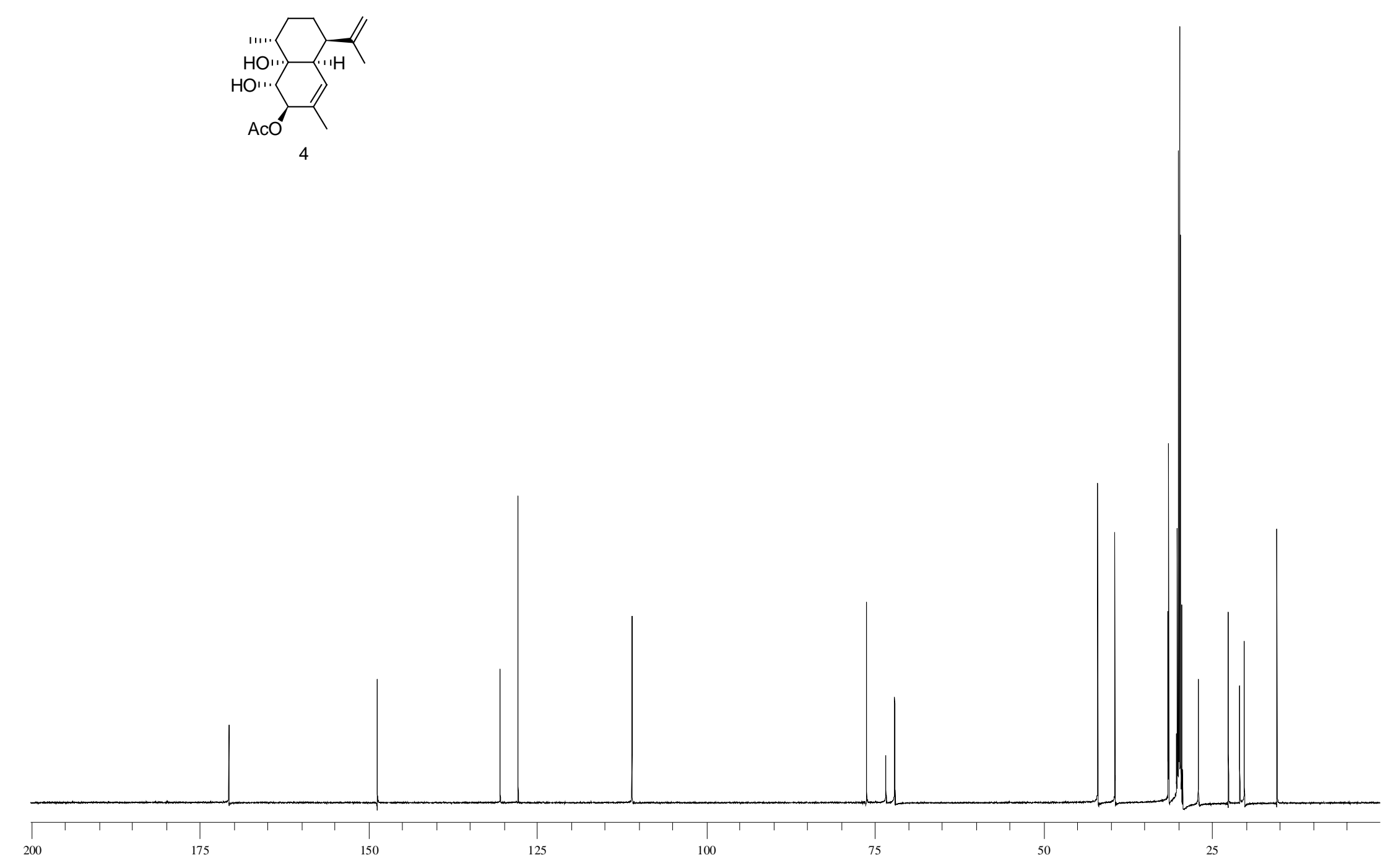




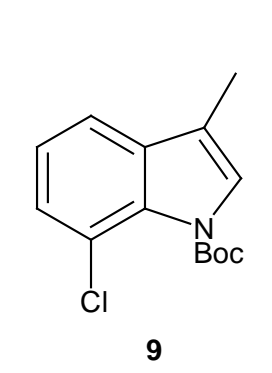

28

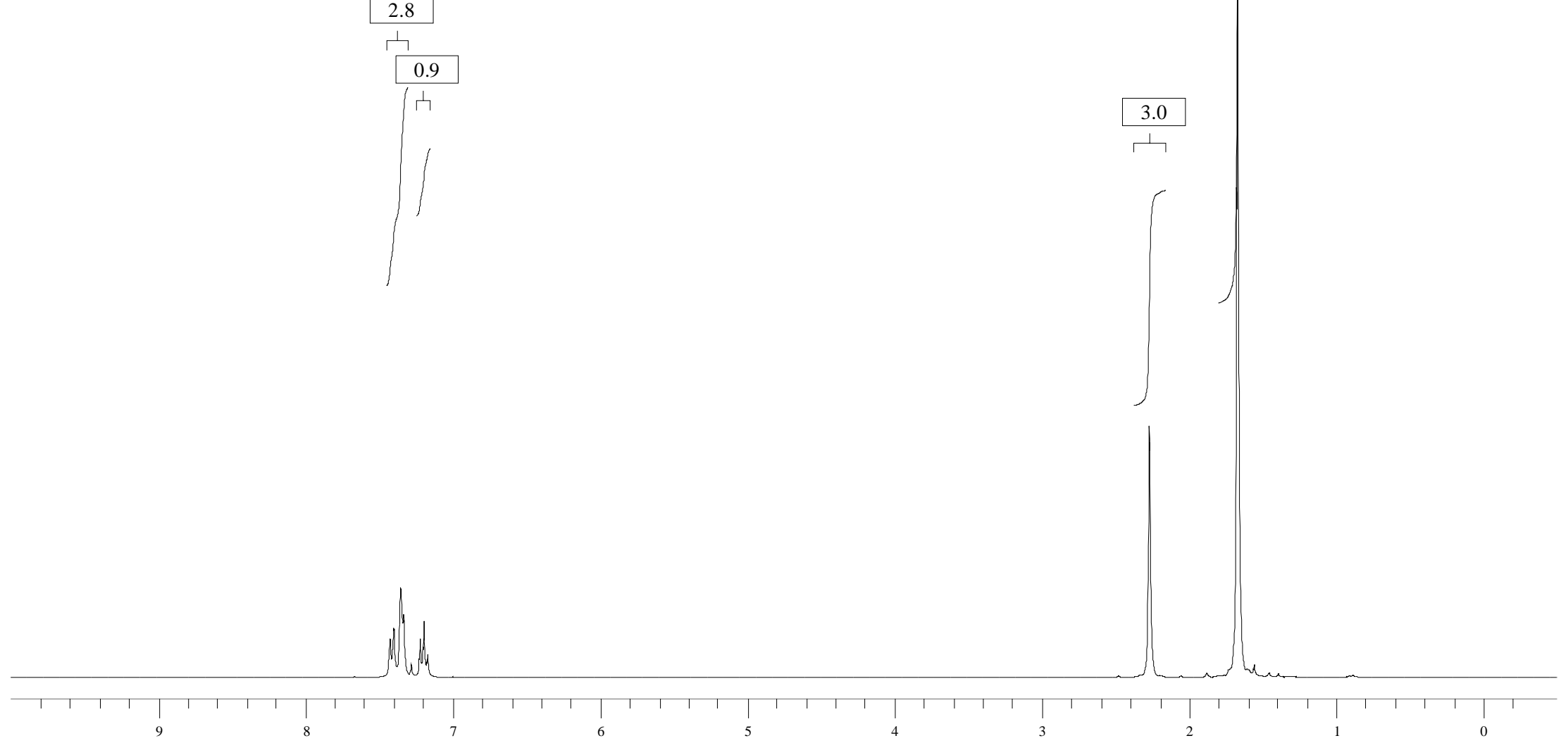




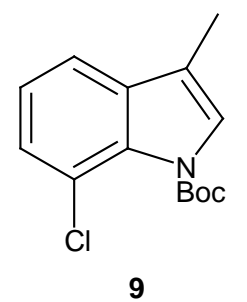

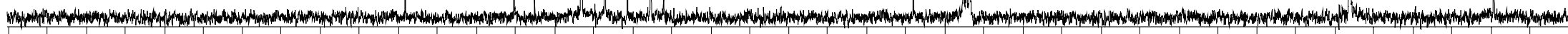




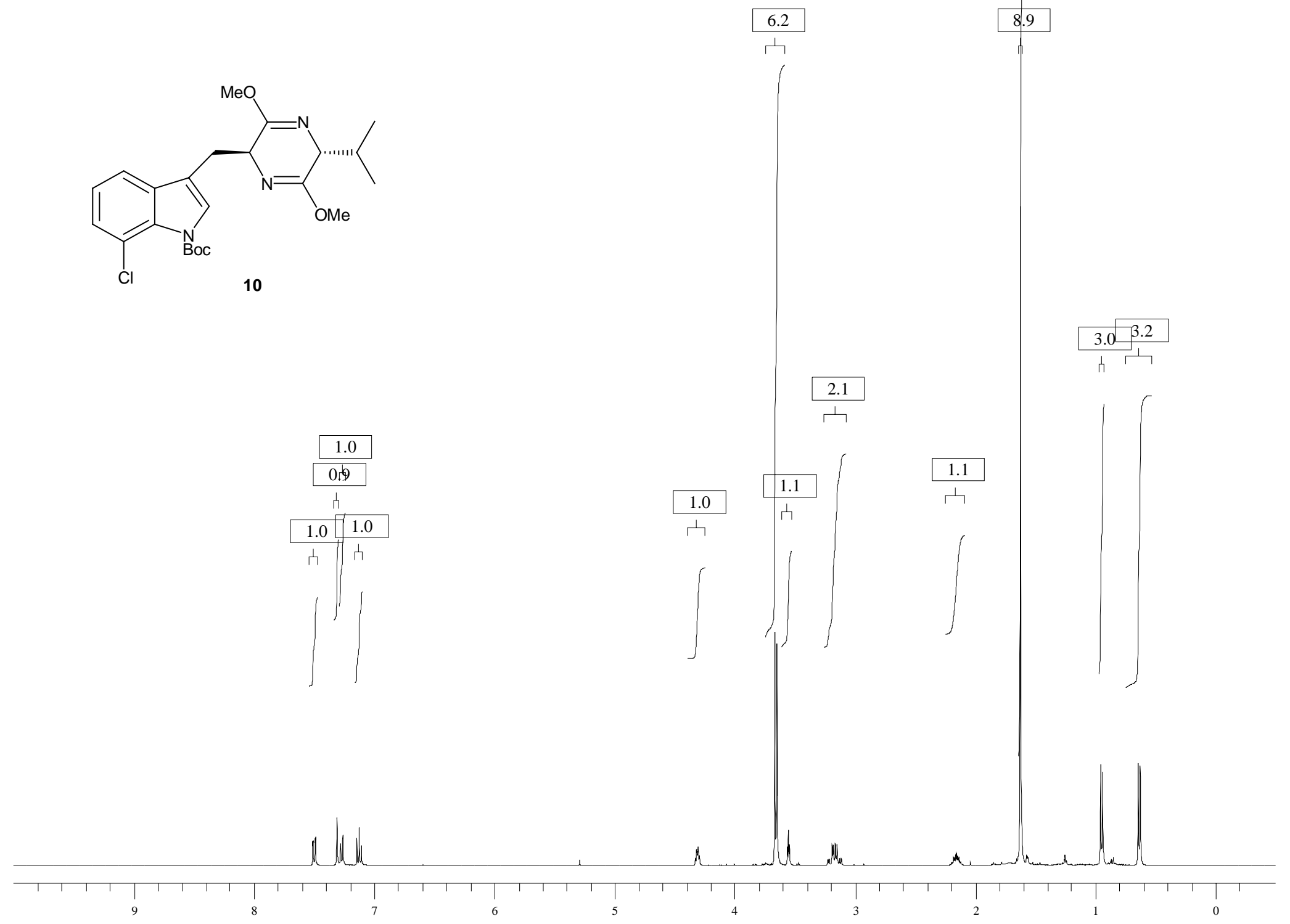




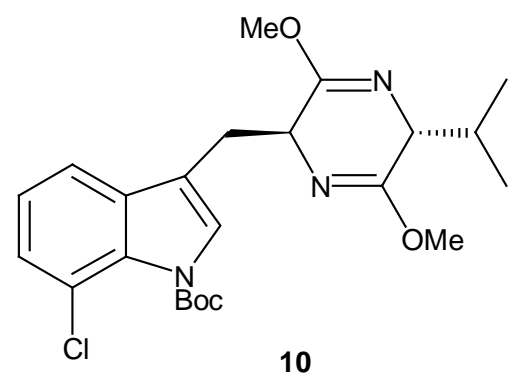




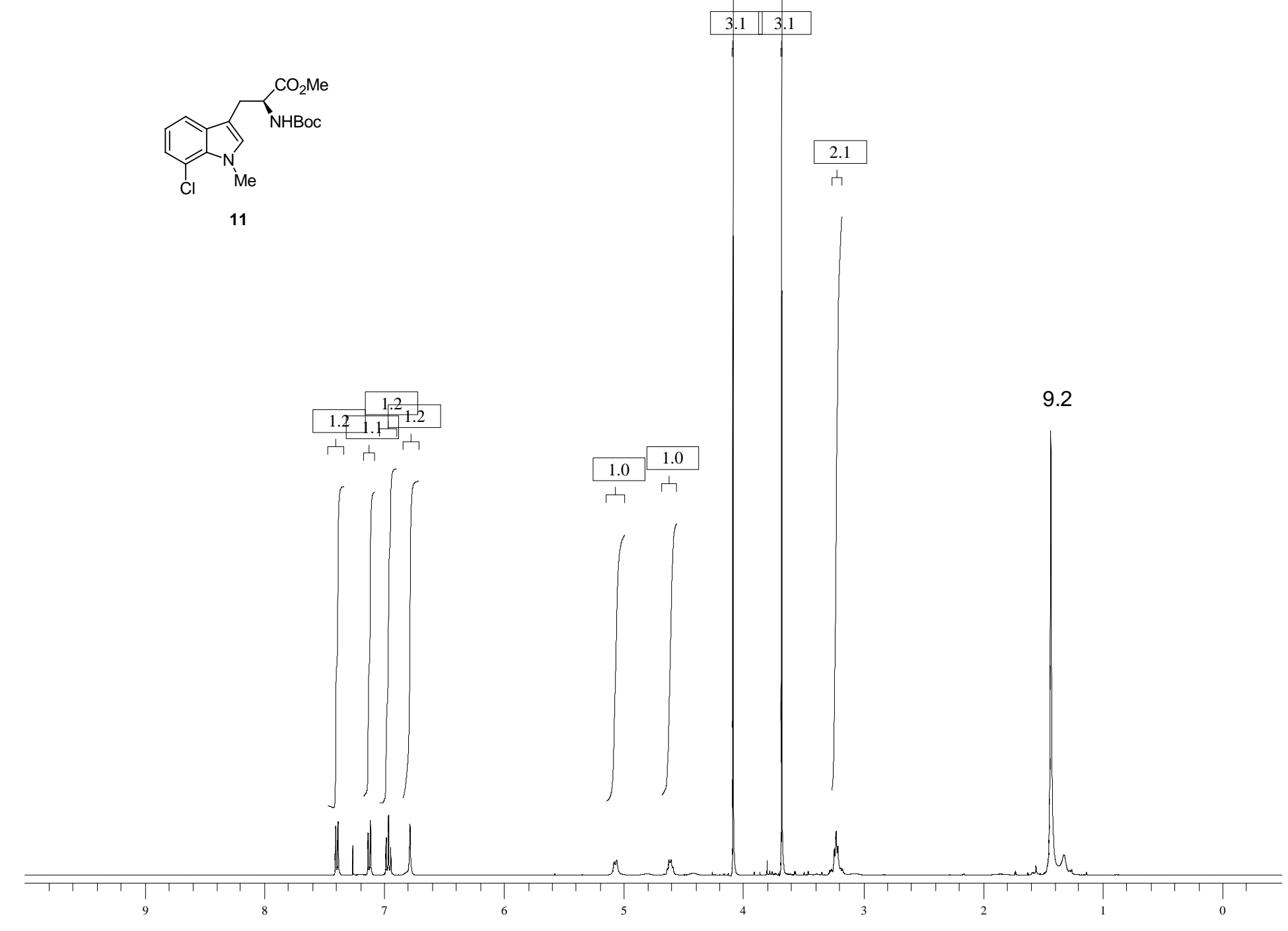




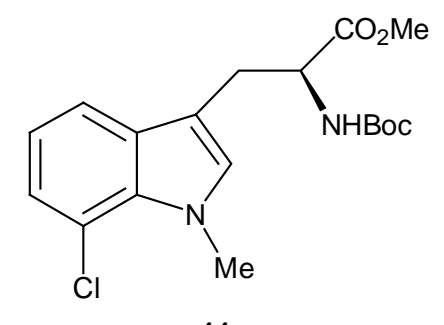

11

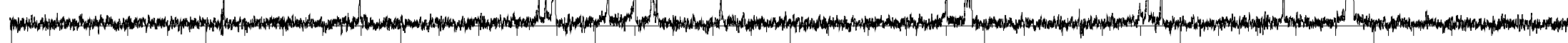
200

175

150

125

100

75

25 

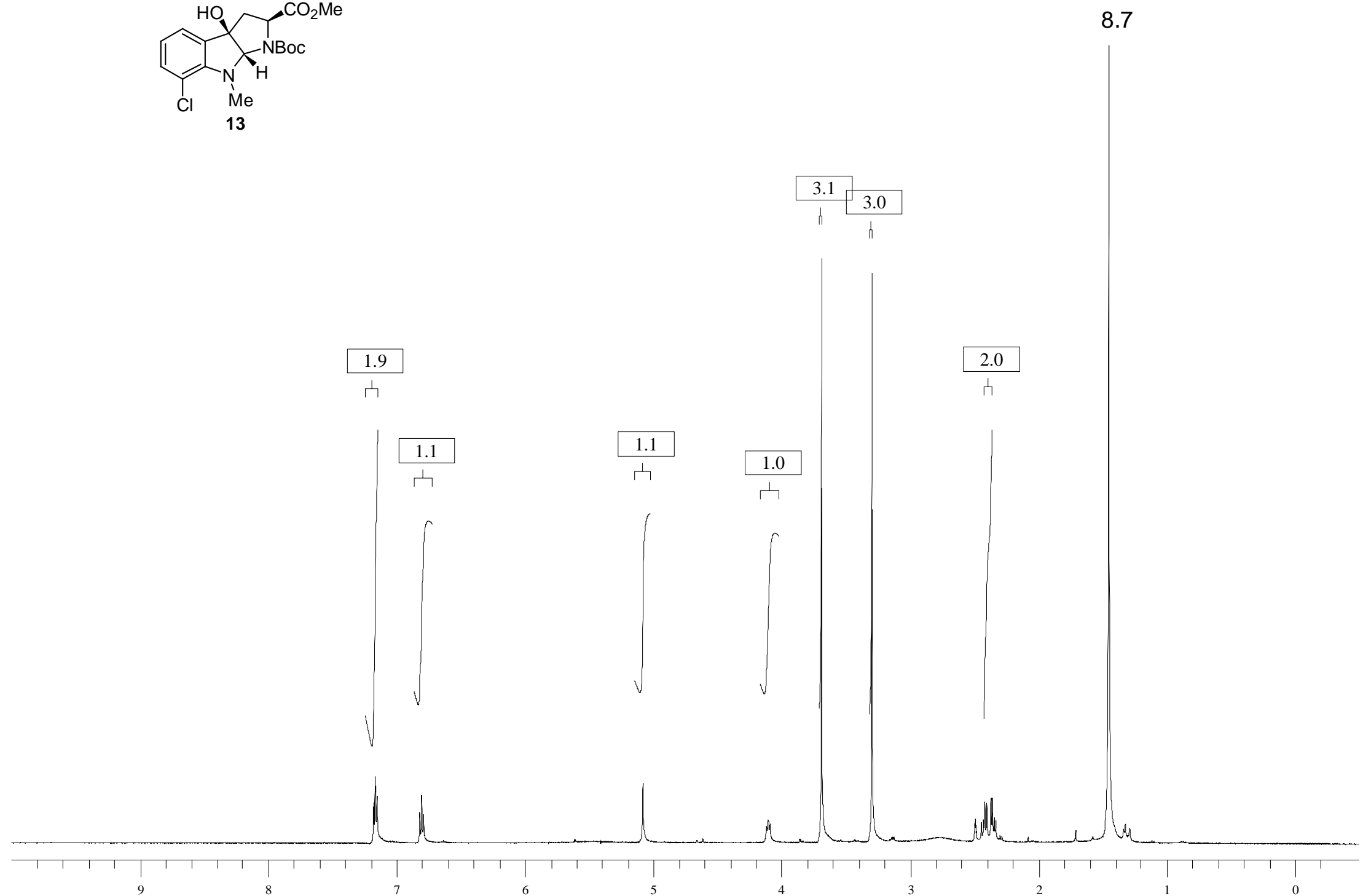


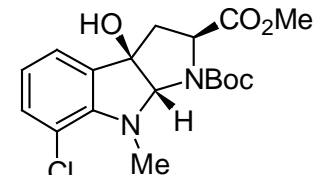

13

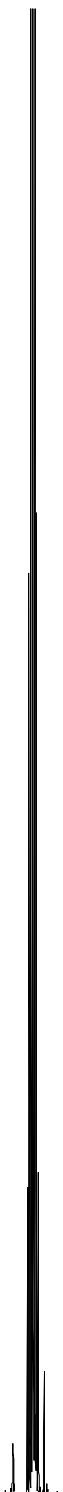

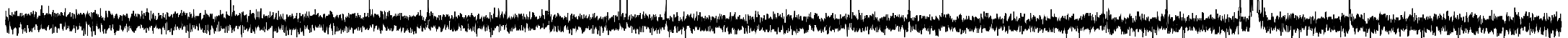

$$
\prod_{200}
$$

175

150

125

100

75

S-10 


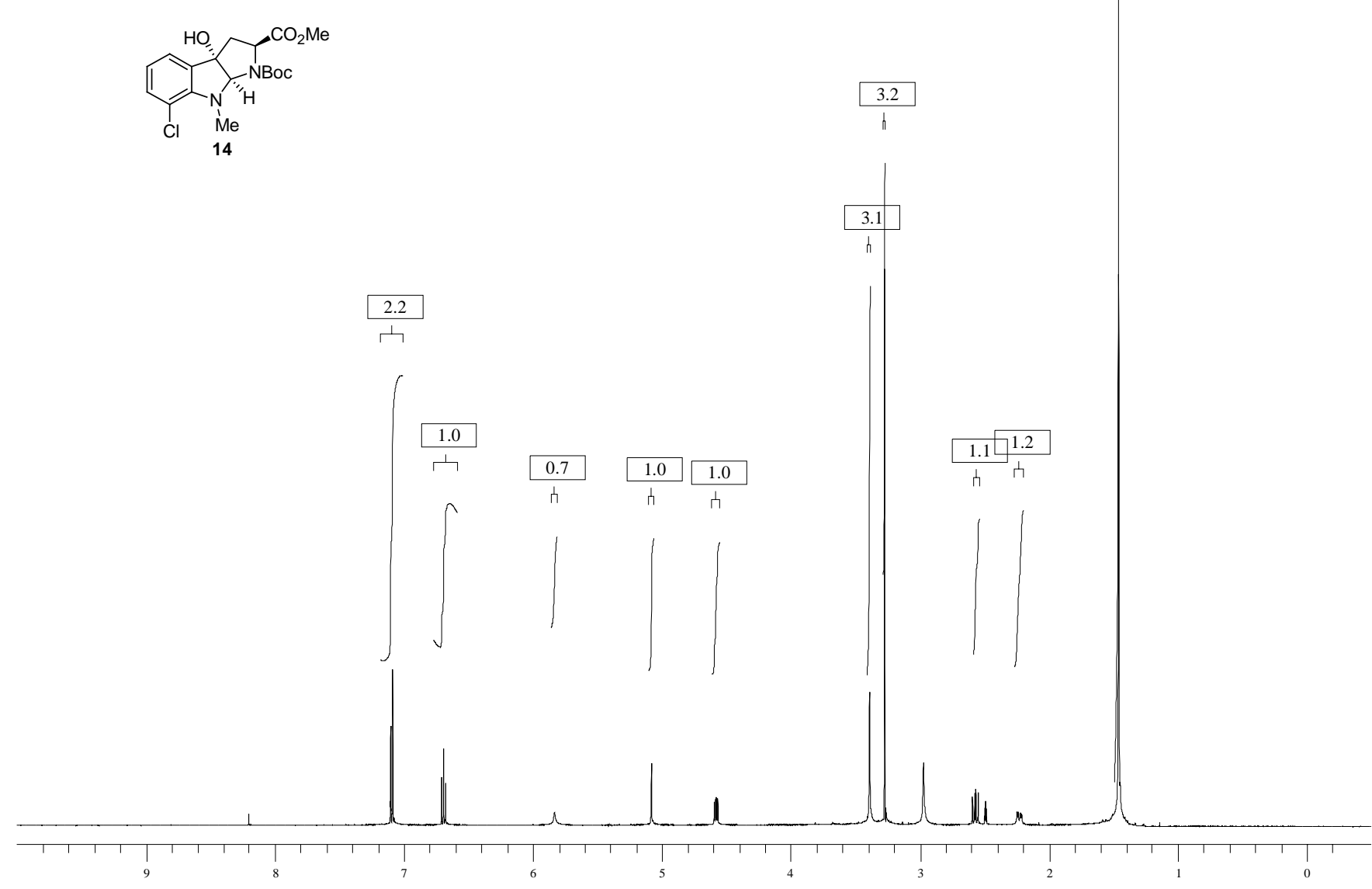




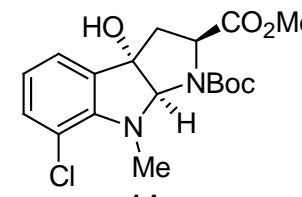

14 


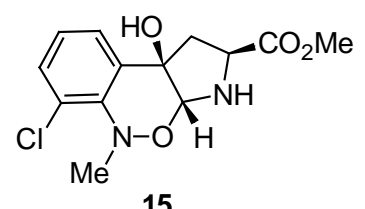

15

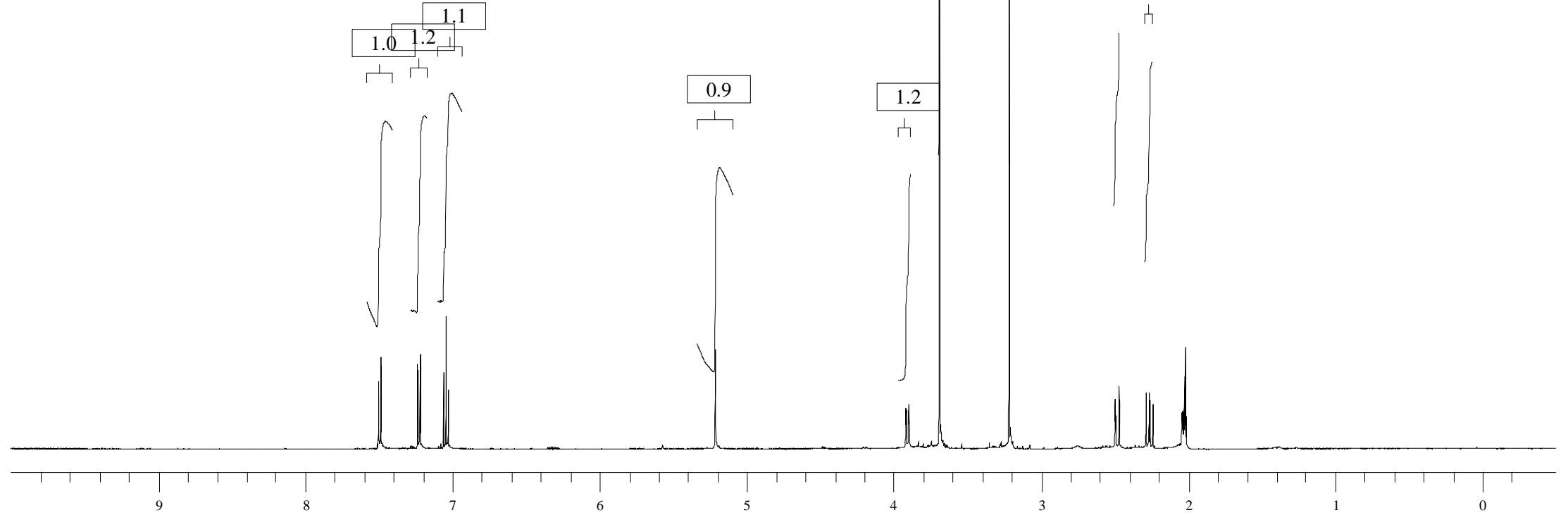




$$
\text { (15) }
$$

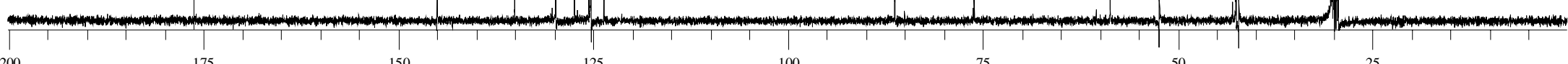



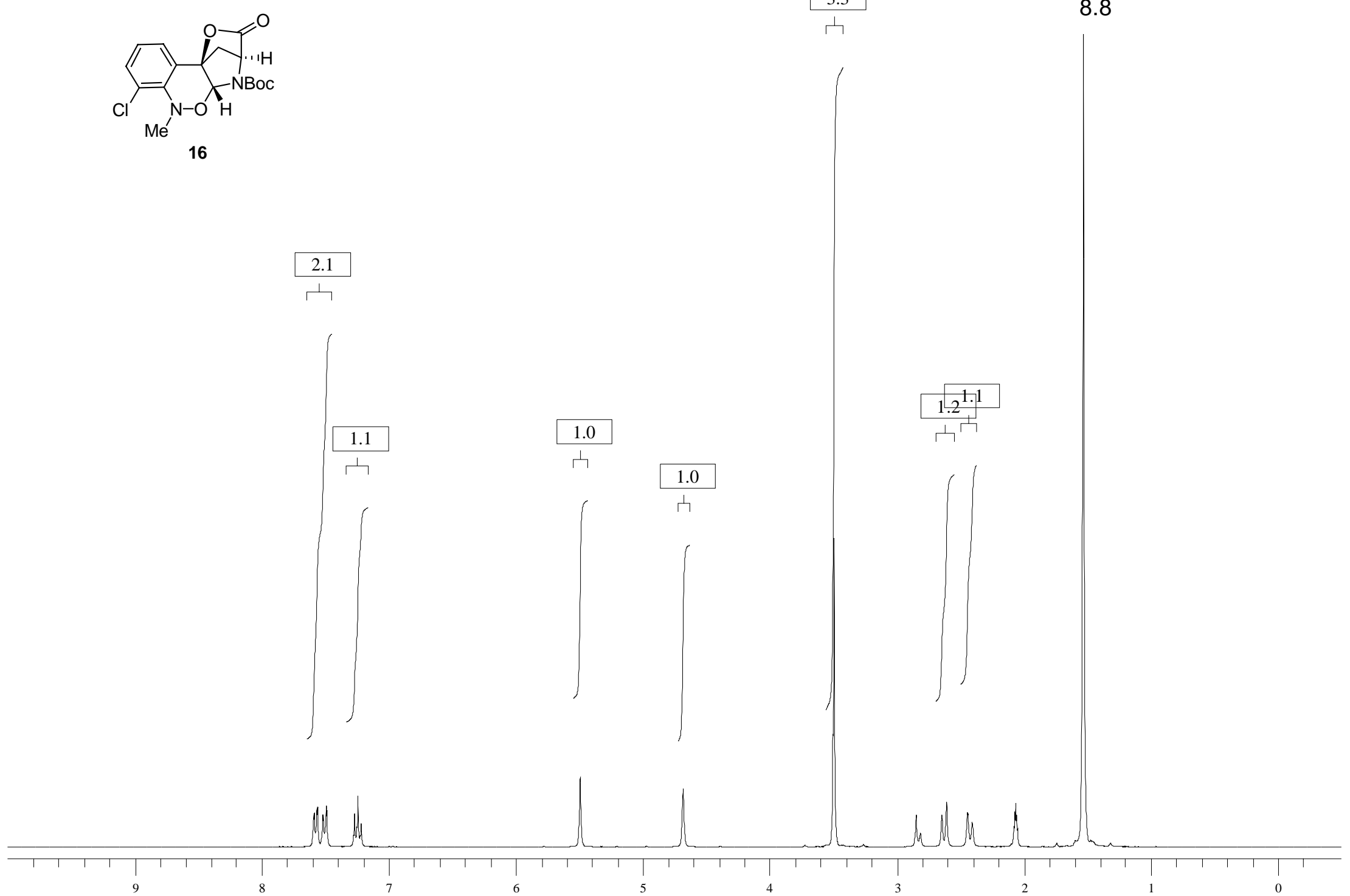


$$
\text { (16) }
$$

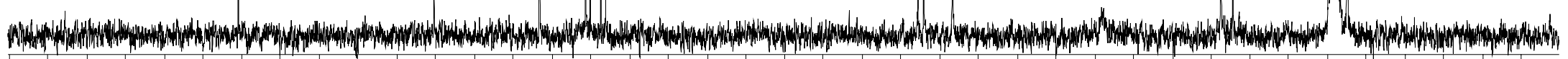

$$
\Gamma_{200}
$$

125

100

50

25 


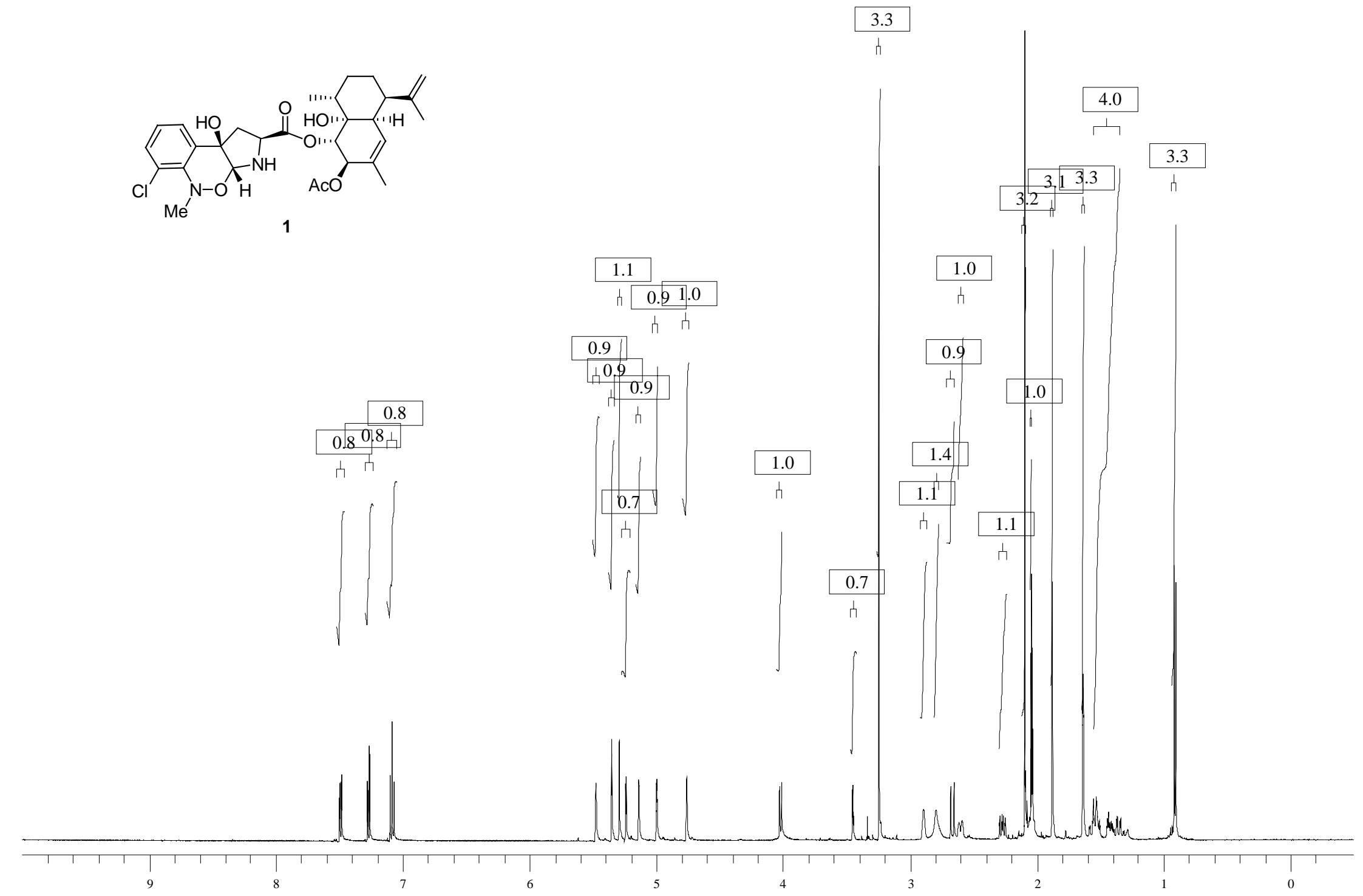




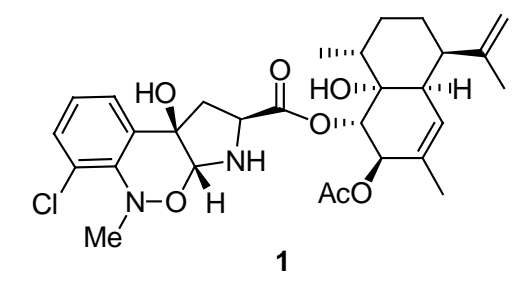

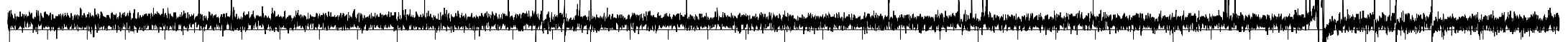




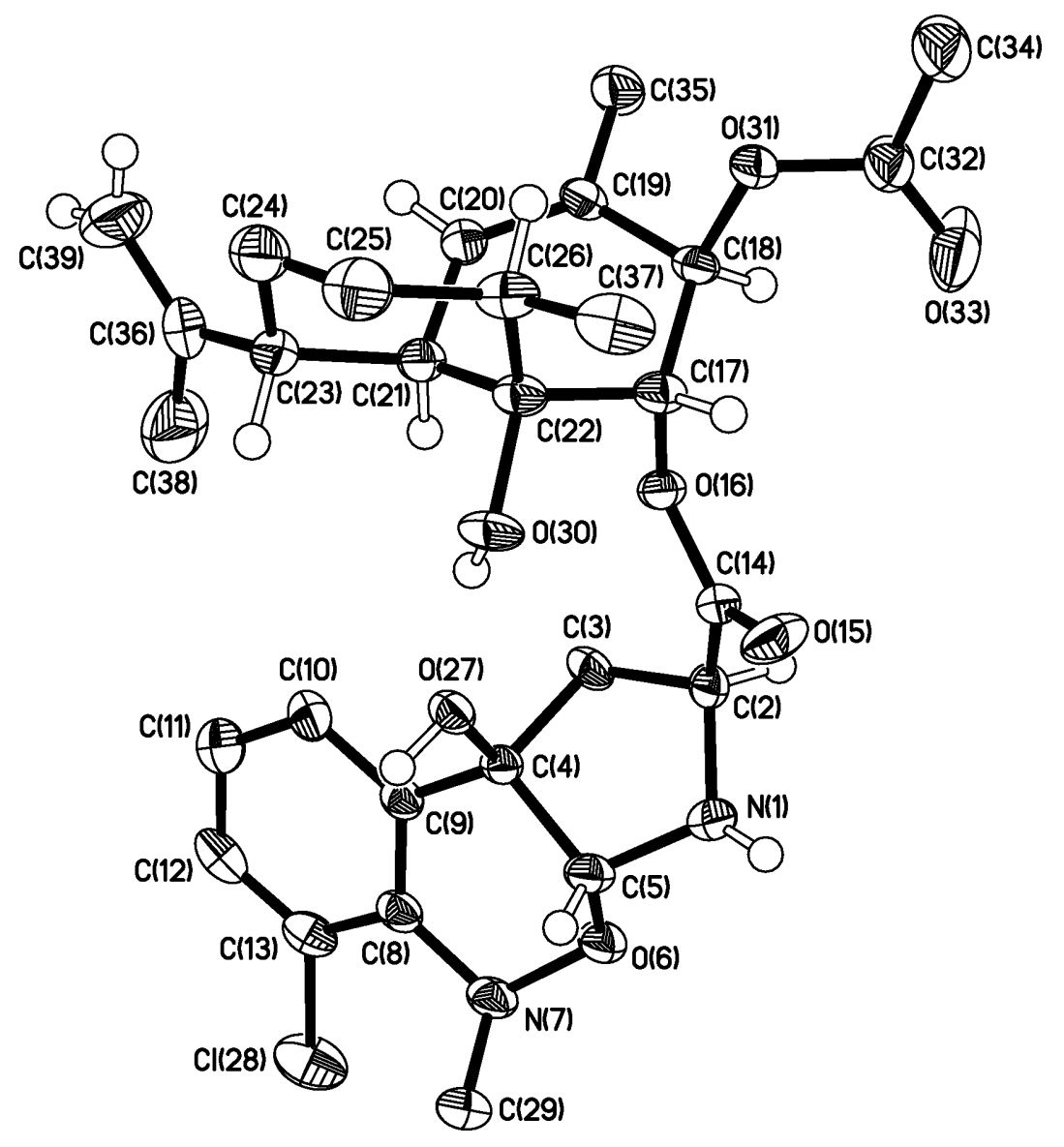

Fig. 1. The molecular structure of $\mathbf{1}$ (CCDC 234954, 30\% probability ellipsoids). 


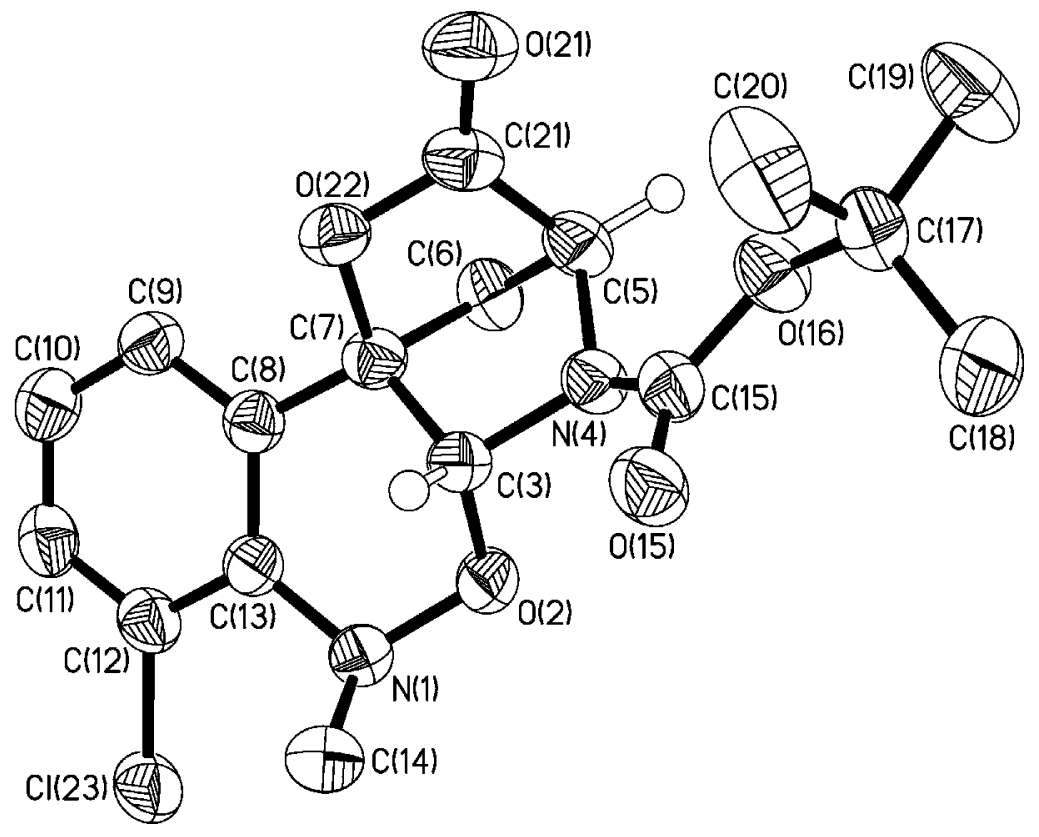

Fig. 2. The molecular structure of $\mathbf{1 6}$ (CCDC 234955, 30\% probability ellipsoids). 